\title{
Noncovalent Bonds, Spectral and Thermal Properties of Substituted Thiazolo[2,3-b][1,3]thiazinium Triiodides
}

\author{
Irina Yushina *(D), Natalya Tarasova, Dmitry Kim, Vladimir Sharutin and Ekaterina Bartashevich \\ South Ural State University (National Research University) 76, Lenin Prospect, Chelyabinsk 454080, Russia; \\ tarasovanm@susu.ru (N.T.); kimdg@susu.ru (D.K.); sharutinvv@susu.ru (V.S.); bartashevichev@susu.ru (E.B.) \\ * Correspondence: iushinaid@susu.ru
}

Received: 31 August 2019; Accepted: 23 September 2019; Published: 28 September 2019

check for updates

\begin{abstract}
The interrelation between noncovalent bonds and physicochemical properties is in the spotlight due to the practical aspects in the field of crystalline material design. Such study requires a number of similar substances in order to reveal the effect of structural features on observed properties. For this reason, we analyzed a series of three substituted thiazolo[2,3-b][1,3]thiazinium triiodides synthesized by an iodocyclization reaction. They have been characterized with the use of X-ray diffraction, Raman spectroscopy, and thermal analysis. Various types of noncovalent interactions have been considered, and an S ... I chalcogen bond type has been confirmed using the electronic criterion based on the calculated electron density and electrostatic potential. The involvement of triiodide anions in the I ... I halogen and S ... I chalcogen bonding is reflected in the Raman spectroscopic properties of the I-I bonds: identical bond lengths demonstrate different wave numbers of symmetric triiodide vibration and different values of electron density at bond critical points. Chalcogen and halogen bonds formed by the terminal iodine atom of triiodide anion and numerous cation ... cation pairwise interactions can serve as one of the reasons for increased thermal stability and retention of iodine in the melt under heating.
\end{abstract}

Keywords: chalcogen bond; halogen bond; triiodide anion; Raman spectroscopy; thermal analysis; thiazolo[2,3-b][1,3]thiazinium salts

\section{Introduction}

A great number of relatively strong noncovalent interactions in $\mathrm{N}$ - and S-heterocyclic polyiodides, such as halogen and chalcogen bonds, can not only promote the stability and diversity of possible polyiodide organization, but help in the organization of anion transport, chiral synthesis, and organocatalysis [1]. For electrostatically driven noncovalent bonds [2], the electrophilic site-the electron deficient region on the extension of the covalent bond of one atom-is orientated towards the nucleophilic fragment in another molecule. The International Union of Pure and Applied Chemistry (IUPAC) definition of halogen [3] and chalcogen bonds [4] is based on a series of quantitative features from structural, theoretical and spectral points of view. The development of noncovalent bond characterization in crystals includes the analysis of distribution features of the electrostatic potential [5], the quantum theory of atoms in molecules (QTAIM) methodology [6], electron localization function (ELF) [7], Laplacian of electron density [8], facilities of reduced density gradient (RDG) and analysis using the noncovalent interactions (NCI) method [9].

Variation of the N- and S-containing heterocyclic cations is useful for the investigation of bonding properties in organic polyiodide crystals. The chemistry of polyhalides has attracted particular attention due to the vast diversity of applicable properties related to the ability of halogens to form different types 
of contacts [10-15]. Polyiodides represent an absolute majority among polyhalide structures [16-21]. The interest in polyiodide derivatives is based on their enormous structural diversity of packing motives resulting in the formation of anionic ribbons, layers, channels and sheets [22-24]. The intense development of semiconductor [25-28] and nonlinear optical materials [29] based on polyiodides [30] necessitates obtaining and comprehensively investigating new molecular and crystal structures with specific properties. Structural investigation of the polarization effect or charge transfer in ionic complexes of thioamides with iodine is quite useful for explaning of the activity of some anti-thyroid drugs and antibiotics in vivo [31-36]. In all cases, the specific moiety responsible for biological activity is the released diiodine. The possibility of binding and releasing iodine from complex polyiodide structures finds its practical application in water disinfection [37] and the sorption of radioactive isotopes of iodine, such as I-131, and radiolabeling in vivo [38]. The particular significance of $\mathrm{I}^{3-} / \mathrm{I}^{-} \cdot \mathrm{I}_{2}$ interconversion is reflected in the tasks of the novel design of ionic liquids and iodine-containing solid electrolytes for dye-sensitized solar cells (DSSC) [39].

The use of such heterocyclic systems as thiazolo[2,3-a]isoquinolinium cations [40] is very promising in this regard. Syntheses of the related systems, such as $2 H$-benzo[4,5]thiazolo[2,3-b][1,3] thiazin-5-ium, are superficially described in the literature [41], and only a few examples of 3,5,6,7- tetrahydro-2H-thiazolo[2,3-b][1,3]thiazin-4-ium synthesis and transformation have been described [42-44] in the context of their biological activity.

The determination of crystal structure in polyiodide systems is highly necessary because of the ability of polyiodides to form mixtures of different compositions, to absorb excess iodine in a precipitate, and to form a melt or release iodine under storage conditions. Raman spectroscopy has earned a reputation as an extremely sensitive method [45] capable of distinguishing a variety of bonding peculiarities in the polyiodide anion [46]. It reliably characterizes polyiodides with various organic or inorganic cations, revealing typical structural units, such as the triiodide anion $\left(100-120 \mathrm{~cm}^{-1}\right)$, bound iodine (140-180 $\left.\mathrm{cm}^{-1}\right)$, and the pentaiodide anion $\left(140-160 \mathrm{~cm}^{-1}\right)$ [30]. The role of thermal analysis is very important in the field of iodophoric materials and DSSC device development, where the questions of thermal stability, features of source decomposition, and iodine release are of particular importance [47].

Sometimes, for the S ... I interactions in N- and S-heterocyclic polyiodides, the main question is which atom delivers the electrophilic site for bonding. If the I atom acts as the electrophilic site provider, we can conclude that this is a halogen bond. If the $S$ atom delivers the electrophilic site, then it is a chalcogen bond. Thus, the relatively strong and charge-assisted S ... I interactions in organic polyiodide crystals can be interpreted as either halogen or chalcogen bonds depending on the electron density distribution and mutual orientation of their electrophilic and nucleophilic sites. In order to figure out how the polarization effect or charge redistribution are directed, it is important to understand which atom donates electrons and which one delivers the electrophilic site for bonding. The categorization of chalcogen and halogen bonds in debatable cases can be performed using previously suggested [48] electronic criterion: "along the line between bound atoms, the minimum of electrostatic potential is always located from the side of nucleophilic site; the minimum of electron density is closer to electrophilic site provider".

Our research is focused on a series of thiazolo[2,3-b][1,3]thiazinium triiodides and on the study of how the spectral properties and thermal stability of these crystals are influenced by the type and features of the S... I noncovalent bond.

\section{Materials and Methods}

\subsection{Synthesis}

Thiazolo[2,3-b][1,3]thiazin-5-ium cations of compounds 2a-c (Figure 1) are formed via a halocyclization reaction by the action of the iodine molecule on an unsaturated bond of S-allylic or S-butenylic substituents. The compounds 3-iodo-4-phenyl-3,4-dihydro-2H-benzo[4,5]thiazolo[2,3-b] 
[1,3]thiazin-5-ium (2a) and 4-(iodomethyl)-3,4-dihydro-2H-benzo[4,5]thiazolo[2,3-b][1,3]thiazin-5-ium triiodides $(2 \mathrm{~b})$ were obtained for the first time. Compounds $2 \mathrm{a}, \mathrm{b}$ with aromatic systems in their structures crystallized faster than triiodide $2 \mathrm{c}$ with a partially unsaturated cation. High quality crystals of compound $2 \mathrm{c}$ were obtained in the mixture with a corresponding monoiodide only after recrystallization.

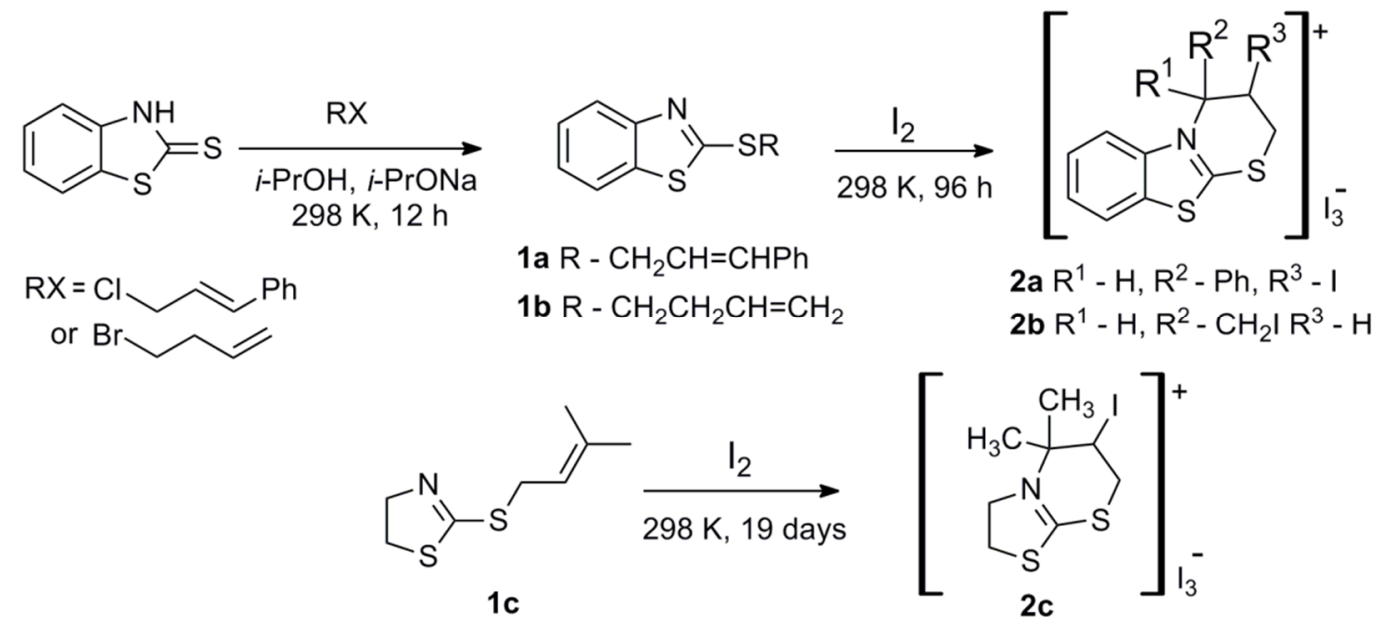

Figure 1. Iodocyclization of compounds $1 \mathrm{a}-\mathrm{c}$ resulting in corresponding triiodides $2 \mathrm{a}-\mathrm{c}$.

The iodine solution was prepared as follows: anhydrous dioxane and $\mathrm{CH}_{2} \mathrm{Cl}_{2}$ were refluxed for half an hour with solid iodine. The solution was decanted from an excess of iodine and cooled. Te concentration of iodine was determined by titration with sodium thiosulphate solution in three replicates. The resulting concentration of iodine in dioxane was $73.9 \pm 0.05 \mathrm{mg} / \mathrm{mL}$, and $50.5 \pm 0.05 \mathrm{mg} / \mathrm{mL}$ in $\mathrm{CH}_{2} \mathrm{Cl}_{2}$.

Benzothiazole-2-thione ( $2 \mathrm{~g} ; 12 \mathrm{mmol}$ ) was dissolved in $20 \mathrm{~mL}$ i-PrOH with $12 \mathrm{mmol}$ i-PrONa; then, $12 \mathrm{mmol}$ alkenyl bromide (cinnamyl chloride or 4-bromobut-1-ene) was added dropwise. The mixture was stirred for $12 \mathrm{~h}$ at $298 \mathrm{~K}$ and filtered. The solution was diluted with $50 \mathrm{~mL}$ of water and extracted with three portions of $\mathrm{CH}_{2} \mathrm{Cl}_{2}(50 \mathrm{~mL}, 25 \mathrm{~mL}$, and $25 \mathrm{~mL}$ ). The extracts were combined, washed with $20 \mathrm{~mL} 5 \% \mathrm{H}_{2} \mathrm{SO}_{4}, 15 \mathrm{~mL}$ distilled water, and dried over $\mathrm{CaCl}_{2}$. The solvent was evaporated under reduced pressure, giving compounds $1 \mathrm{a}, \mathrm{b}$ in the form of yellow oil.

The compound 2-(cinnamylsulfanyl)benzo[d]thiazole (1a) was analyzed by ${ }^{1} \mathrm{H}$ NMR $\left(\mathrm{CDCl}_{3}\right.$, ppm): $7.90\left(\mathrm{~d}, \mathrm{~J}=8.2 \mathrm{~Hz}, \mathrm{H}_{\mathrm{Ar}}\right) ; 7.74\left(\mathrm{~d}, \mathrm{~J}=7.9 \mathrm{~Hz}, \mathrm{H}_{\mathrm{Ar}}\right) ; 7.44-7.38\left(\mathrm{~m}, \mathrm{H}_{\mathrm{Ar}}\right) ; 7.38-7.32\left(\mathrm{~m}, 2 \mathrm{H}_{\mathrm{Ar}}\right)$; 7.31-7.26 (m, $\left.\mathrm{H}_{\mathrm{Ar}}\right) ; 7.25-7.20\left(\mathrm{~m}, \mathrm{H}_{\mathrm{Ar}}\right) ; 6.70(\mathrm{~d}, \mathrm{~J}=15.7 \mathrm{~Hz},=\mathrm{CH}-) ; 6.37(\mathrm{dt}, \mathrm{J}=15.0,7.3 \mathrm{~Hz},=\mathrm{CH}-) ; 4.17$ $\left(2 \mathrm{H}, \mathrm{d}, \mathrm{J}=7.3 \mathrm{~Hz},-\mathrm{CH}_{2}-\right.$ ). It was also analyzed by ${ }^{13} \mathrm{C}$ NMR (dimethyl sulfoxide-d6 (DMSO-d6), ppm): 166.21 ; 153.06; 136.31; 135.25; 134.27; 128.54 (2C); 127.87; 126.45 (2C); 126.04; 124.26; 123.45; 121.51; 120.96 ; 36.06. Elemental analysis calc. (\%) for $\mathrm{C}_{16} \mathrm{H}_{13} \mathrm{NS}_{2}: \mathrm{C}, 67.81 ; \mathrm{H}, 4.62 ; \mathrm{N}, 4.94$; found: $\mathrm{C}, 67.60 ; \mathrm{H}$, $4.71 ; \mathrm{N}, 4.88$.

The compound 2-(butenylsulfanyl)benzo[d]thiazole (1b) was analyzed by ${ }^{1} \mathrm{H}$ NMR: $\left(\mathrm{CDCl}_{3}, \mathrm{ppm}\right)$ : $7.86\left(\mathrm{~m}, \mathrm{H}_{\mathrm{Ar}}\right) ; 7.75\left(\mathrm{~m}, \mathrm{H}_{\mathrm{Ar}}\right) ; 7.41\left(\mathrm{~m}, \mathrm{H}_{\mathrm{Ar}}\right) ; 7.29\left(\mathrm{~m}, \mathrm{H}_{\mathrm{Ar}}\right) ; 5.89(\mathrm{~m},=\mathrm{CH}) ; 5.13\left(2 \mathrm{H}, \mathrm{m},=\mathrm{CH}_{2}\right) ; 3.43(2 \mathrm{H}, \mathrm{t}, \mathrm{J}$ $\left.=7.3 \mathrm{~Hz}, \mathrm{SCH}_{2}\right) ; 2.59\left(2 \mathrm{H}, \mathrm{m},-\mathrm{CH}_{2}-\right) .{ }^{13} \mathrm{C}$ NMR (DMSO- $\left.d 6, \mathrm{ppm}\right): 166.81 ; 153.28 ; 135.67 ; 135.18 ; 125.97$; $124.14 ; 121.46 ; 120.90 ; 116.92 ; 33.31 ; 32.71$. Elemental analysis calc. (\%) for $\mathrm{C}_{11} \mathrm{H}_{11} \mathrm{NS}_{2}$ : $\mathrm{C}, 59.69 ; \mathrm{H}, 5.01$; N, 6.33; found: C 59.60, H 5.15, N 6.35. The compound 2-(3-methylbutenyl)sulfanyl-4,5-dihydrothiazole (1c) was obtained as described elsewhere [49].

For the compound 3-iodo-4-phenyl-3,4-dihydro-2H-benzo[4,5]thiazolo[2,3-b][1,3]thiazin-5-ium triiodide (2a), compound 1a (1 mmol) was dissolved in $1 \mathrm{~mL}$ anhydrous $\mathrm{CH}_{2} \mathrm{Cl}_{2}$, and $7.11 \mathrm{~mL}$ of a solution of iodine $(50.5 \pm 0.05 \mathrm{mg} / \mathrm{mL})$ was added under stirring. The resulting mixture was kept at room temperature for 4 days. Dark brown crystals were filtered and dried in vacuo (yield $0.46 \mathrm{~g}, 98 \%$ ). It was analyzed by ${ }^{1} \mathrm{H}$ NMR (DMSO- $\left.66, \mathrm{ppm}\right): 8.46-8.42\left(\mathrm{~m}, \mathrm{H}_{\mathrm{Ar}}\right) ; 7.90-7.84\left(\mathrm{~m}, \mathrm{H}_{\mathrm{Ar}}\right) ; 7.78-7.69$ (m, 
$\left.2 \mathrm{H}_{\mathrm{Ar}}\right) ; 7.50-7.43\left(\mathrm{~m}, \mathrm{H}_{\mathrm{Ar}}\right) ; 7.38-7.24\left(\mathrm{~m}, \mathrm{H}_{\mathrm{Ar}}\right) ; 7.01(1 \mathrm{H}, \mathrm{s}, 4-\mathrm{H}) ; 5.69(1 \mathrm{H}, \mathrm{dd}, \mathrm{J}=5.9,3.0 \mathrm{~Hz}, 3-\mathrm{H}) ; 3.70$ $(1 \mathrm{H}, \mathrm{dd}, \mathrm{J}=14.6,3.4 \mathrm{~Hz}, 2-\mathrm{H}) ; 3.40(1 \mathrm{H}, \mathrm{dd}, \mathrm{J}=14.6,2.8 \mathrm{~Hz}, 2-\mathrm{H})$ and ${ }^{13} \mathrm{C}$ NMR (DMSO-d6, ppm): 175.96; 140.67; 135.42; 129.60 (2C); 129.50; 129.18; 128.24; 127.43; 126.15 (2C); 124.53; 114.67; 66.33; 33.78; 17.19. Elemental analysis calc. (\%) for $\mathrm{C}_{16} \mathrm{H}_{13} \mathrm{I}_{4} \mathrm{NS}_{2}$ : C, 24.29; $\mathrm{H}, 1.66 ; \mathrm{N}, 1.77$; found: $\mathrm{C}, 24.31 ; \mathrm{H}, 1.62$; $\mathrm{N}, 1.83$.

For the compounds 4-(iodomethyl)-3,4-dihydro-2H-benzo[4,5]thiazolo[2,3-b][1,3]thiazin-5-ium triiodide (2b) and 6-iodo-5,5-dimethyl-3,5,6,7-tetrahydro-2H-thiazolo[2,3-b][1,3]thiazin-4-ium triiodide (2c): compounds $1 \mathrm{~b}, \mathrm{c}(1 \mathrm{mmol})$ were dissolved in $0.8 \mathrm{~mL}$ anhydrous dioxane, and $7.35 \mathrm{~mL}$ of a solution of iodine $(73.9 \pm 0.05 \mathrm{mg} / \mathrm{mL})$ was added under stirring. The resulting mixture was kept at room temperature for 19 days $(2 \mathrm{~b})$ and 8 days $(2 \mathrm{c})$.

For 4-(iodomethyl)-3,4-dihydro-2H-benzo[4,5]thiazolo[2,3-b][1,3]thiazin-5-ium triiodide (2b): dark brown crystals were filtered and dried in vacuo (yield $0.6 \mathrm{~g}, 91 \%$ ); analysis by ${ }^{1} \mathrm{H}$ NMR (DMSO- $d 6$, ppm): $8.34\left(\mathrm{~d}, \mathrm{~J}=7.7, \mathrm{H}_{\mathrm{Ar}}\right) ; 8.12\left(\mathrm{~d}, \mathrm{~J}=8.5 \mathrm{~Hz}, \mathrm{H}_{\mathrm{Ar}}\right) ; 7.89\left(\mathrm{t}, \mathrm{J}=7.9 \mathrm{~Hz}, \mathrm{H}_{\mathrm{Ar}}\right) ; 7.72\left(\mathrm{t}, \mathrm{J}=7.7 \mathrm{~Hz}, \mathrm{H}_{\mathrm{Ar}}\right)$; 5.58-5.51 (1H, m, 5-CH); 3.76-3.66 (2H, m, $\left.\mathrm{CH}_{2} \mathrm{I}\right) ; 3.65-3.57\left(2 \mathrm{H}, \mathrm{m}, 3-\mathrm{CH}_{2}\right) ; 3.05-2.96\left(1 \mathrm{H}, \mathrm{m}, 4-\mathrm{CH}_{2}\right)$; 2.49-2.41 (1H, m, 4-CH CH $_{2}$ and ${ }^{13} \mathrm{C}$ NMR (DMSO-d6, ppm):: 173.63; 136.67; 126.58; 125.55; 124.89; 121.83; $119.48 ; 112.87 ; 53.15 ; 30.11 ; 21.41$. Elemental analysis calc. $(\%)$ for $\mathrm{C}_{11} \mathrm{H}_{11} \mathrm{I}_{4} \mathrm{NS}_{2}: \mathrm{C}, 18.12 ; \mathrm{H}, 1.52 ; \mathrm{N}$, 1.92; found: $\mathrm{C}, 18.10 ; \mathrm{H}, 1.60 ; \mathrm{N}, 1.89$.

For 6-iodo-5,5-dimethyl-3,5,6,7-tetrahydro-2H-thiazolo[2,3-b][1,3]thiazin-4-ium triiodide (2c): the solvent was decanted and dark brown crystals with a matte surface $(0.43 \mathrm{~g})$ were isolated and dried in vacuo. A portion of the crystals $(0.23 \mathrm{~g})$ was recrystallized from a $5 \mathrm{~mL}$ mixture of i-PrOH DMF (N,N-Dimethylformamide) (3:2). The mixture of small brown and yellow crystals ( $0.15 \mathrm{~g})$ was filtered and dried in vacuo (Figure S1, see Supplementary Materials). The crystal structure of the brown prismatic crystals (2c) was determined using single crystal X-ray diffraction. The impurity of the yellow prismatic crystals, which should presumably relate to the corresponding monoiodide, was separated manually under a microscope, but still did not prove suitable for X-ray diffraction experiments (Figure S1).

\subsection{X-ray Diffraction Refinement}

X-ray diffraction study of single crystals 2a-c was carried out with a Bruker D8 QUEST diffractometer (Mo-K $\alpha$ radiation, $\lambda=0.71073 \AA$, graphite monochromator). Collection, handling of data and refinement of the unit cell parameters, as well as accounting for absorption, were carried out using the SMART and SAINT-Plus programs [50]. All calculations were performed using SHELXTL/PC [51] and OLEX2 [52] software. The structure was solved by direct method and refined by the method of least squares in the anisotropic approximation for non-hydrogen atoms. Crystal data and structure refinement parameters can be found in Table 1. A full list of bond lengths and valence angles are shown in Tables S1 and S2. Full crystallographic data for the compounds can be obtained free of charge from The Cambridge Crystallographic Data Centre (CCDC) (1829960 (2a), 1589820 (2b), 1589819 (2c)).

\subsection{Sample Characterization}

The ${ }^{1} \mathrm{H}$ NMR and ${ }^{13} \mathrm{C}$ NMR spectra were recorded on a Bruker Avance-500 500 and $126 \mathrm{MHz}$ apparatus (tetramethylsilane as an internal standard). The elemental compositions were determined with a Carlo Erba CHNS-O EA 1108 analyzer. Raman spectra were obtained with a NTEGRA Spectra spectrometer using a $632.8 \mathrm{~nm}$ line of the $\mathrm{He}-\mathrm{Ne}^{+}$laser for spectra excitation. The laser power on the sample surface was about $0.2 \mu \mathrm{W}$. We had to take into consideration that due to decreased thermal stability of higher polyiodides [53], the laser power should be thoroughly controlled in order to avoid decomposition under laser explosion. The thermal analysis data have been obtained in the temperature range of $25-700{ }^{\circ} \mathrm{C}$ using Netzsch STA F1 equipment at $10 \mathrm{~K} / \mathrm{min}^{-1}$ heating rates in corundum crucibles in an air atmosphere. The masses of the analyzed samples were $2.0-2.2 \mathrm{mg}$. 
Table 1. Crystal data and structure refinement for triiodides 2a-c.

\begin{tabular}{|c|c|c|c|}
\hline Structure & $2 a$ & $2 b$ & $2 c$ \\
\hline Empirical formula & $\mathrm{C}_{16} \mathrm{H}_{13} \mathrm{NS}_{2} \mathrm{I}_{4}$, & $\mathrm{C}_{11} \mathrm{H}_{11} \mathrm{NS}_{2} \mathrm{I}_{4}$, & $\mathrm{C}_{8} \mathrm{H}_{13} \mathrm{NS}_{2} \mathrm{I}_{4}$ \\
\hline Temperature (K) & 293 & 293 & 296.15 \\
\hline Crystal system & triclinic & triclinic & monoclinic \\
\hline Space group & P-1 & P-1 & $\mathrm{P} 21 / \mathrm{n}$ \\
\hline a $(\AA)$ & $9.775(7)$ & $7.913(5)$ & $12.1447(7)$ \\
\hline $\mathrm{b}(\AA)$ & $9.868(6)$ & $7.994(5)$ & $10.2762(5)$ \\
\hline$c(\AA)$ & $12.890(8)$ & $14.883(11)$ & 13.9862(7) \\
\hline$\alpha\left(^{\circ}\right)$ & $96.416(19)$ & $101.68(3)$ & 90 \\
\hline$\beta\left(^{\circ}\right)$ & $98.49(2)$ & $96.33(3)$ & $108.053(2)$ \\
\hline$\gamma\left({ }^{\circ}\right)$ & $117.72(4)$ & $101.22(3)$ & 90 \\
\hline Volume $\left(\AA^{3}\right)$ & 1065.24 & 893.29 & $1659.57(15)$ \\
\hline $\mathrm{Z}$ & 2 & 2 & 4 \\
\hline Density $\left(\mathrm{g} / \mathrm{cm}^{3}\right)$ & 2.466 & 2.710 & 2.781 \\
\hline$\mu,\left(\mathrm{mm}^{-1}\right)$ & 6.045 & 7.195 & 7.74 \\
\hline$F(000)$ & 720.0 & 653.4 & 1242.9 \\
\hline Crystal size $(\mathrm{mm})$ & $0.25 \times 0.14 \times 0.11$ & $0.77 \times 0.27 \times 0.22$ & $0.47 \times 0.29 \times 0.17$ \\
\hline $2 \theta$ range of data collection (deg) & 5.9 to 59.22 & 5.66 to 66.48 & 6.12 to 79.2 \\
\hline & $-13 \leq h \leq 13$ & $-12 \leq \mathrm{h} \leq 12$ & $-21 \leq \mathrm{h} \leq 21$ \\
\hline Range of refraction indices & $\begin{array}{l}-13 \leq \mathrm{k} \leq 13 \\
-17 \leq 1 \leq 17\end{array}$ & $\begin{array}{l}-12 \leq \mathrm{k} \leq 12 \\
-22 \leq 1 \leq 22\end{array}$ & $\begin{array}{l}-18 \leq \mathrm{k} \leq 18 \\
-24 \leq 1 \leq 25\end{array}$ \\
\hline Measured reflections & 47057 & 52396 & 81480 \\
\hline Independent reflections & $\begin{array}{c}5968\left(R_{\text {int }}=0.0346,\right. \\
R_{\text {sigma }}=0.0186\end{array}$ & $\begin{array}{c}6839\left(R_{\text {int }}=0.0357\right. \\
\left.R_{\text {sigma }}=0.0208\right)\end{array}$ & $\begin{array}{c}9984\left(R_{\text {int }}=0.0432,\right. \\
\left.R_{\text {sigma }}=0.0315\right)\end{array}$ \\
\hline Refinement variables & 211 & 165 & 142 \\
\hline Goodness-of-fit on $\mathrm{F}^{2}$ & 1.039 & 1.049 & 1.104 \\
\hline $\mathrm{R}$ factors for $\mathrm{F}^{2}>2 \sigma\left(\mathrm{F}^{2}\right)$ & $\begin{array}{r}\mathrm{R}_{1}=0.0283 \\
w \mathrm{R}_{2}=0.0623\end{array}$ & $\begin{array}{r}\mathrm{R}_{1}=0.0450 \\
w \mathrm{R}_{2}=0.1007\end{array}$ & $\begin{array}{l}\mathrm{R}_{1}=0.0543 \\
w \mathrm{R}_{2}=0.117\end{array}$ \\
\hline $\mathrm{R}$ factors for all reflections & $\begin{array}{c}\mathrm{R}_{1}=0.0431 \\
w \mathrm{R}_{2}=0.0683\end{array}$ & $\begin{array}{c}\mathrm{R}_{1}=0.0611 \\
w \mathrm{R}_{2}=0.1098\end{array}$ & $\begin{array}{c}\mathrm{R}_{1}=0.1107 \\
w \mathrm{R}_{2}=0.1171\end{array}$ \\
\hline $\begin{array}{l}\text { Residual electron density } \\
\qquad(\min / \max )\left(e / \AA^{3}\right)\end{array}$ & $0.61 /-1.29$ & $1.98 /-2.24$ & $3.13 /-3.71$ \\
\hline
\end{tabular}

\subsection{Theoretical Calculations}

Periodic Kohn-Sham calculations were performed in the CRYSTAL17 program package [54], employing the B3LYP exchange-correlation functional. K-point sampling was done using a Monkhorst-Pack grid of $8 \times 8 \times 8$. The modified DZVP basis set was used for iodine atoms [55], and the 6-31G** Gaussian type basis sets were used for the C, H, N and S atoms from [56]. Calculations of the electron localization function (ELF) [7] distribution in the planes, in which the S...I interactions lay, were performed using the TOPOND program [57]. The values of the electron density (ED) and electrostatic potential (ESP) along the line between the $S$ and I atoms were derived due to the additional output procedure in TOPOND approximating the interatomic line by 200 points.

\section{Results and Discussion}

\subsection{Structural Characterization of Compounds $2 a-c$}

The crystal structures of compounds $2 \mathrm{a}, \mathrm{b}$ belong to the triclinic crystal system. The crystallographic cell consists of two ionic pairs of $2 \mathrm{H}$-benzo[4,5]thiazolo[2,3-b][1,3]thiazin-5-ium cations with triiodide anions. Compound $2 \mathrm{c}$ crystallizes in a monoclinic lattice with four ionic pairs of 3,5,6,7-tetrahydro-2H-thiazolo[2,3-b][1,3]thiazin-4-ium cations with triiodide anions (Figure 2). The summary of geometric parameters of the S...I interactions and bond lengths within triiodide anions can be found in Table 2. 


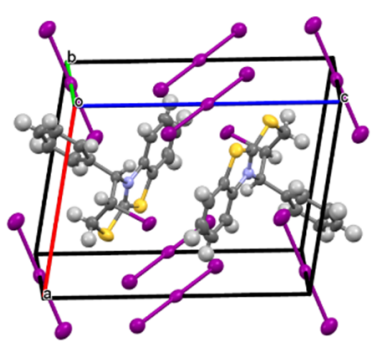

(a)

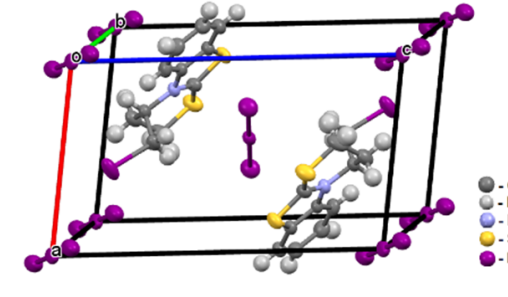

(b)

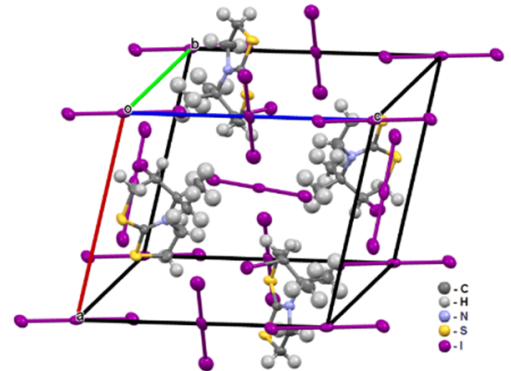

(c)

Figure 2. Crystal packing of 2a (a); $2 b$ (b) and 2c (c) with thermal ellipsoids of $50 \%$ probability, view along the $b$ crystallographic axis.

Table 2. Experimental geometric parameters of S ... I interactions in 2a-c crystal structures.

\begin{tabular}{|c|c|c|c|c|}
\hline & Distance S . . I, Å & C-S ... I Angle, ${ }^{\circ}$ & S ... I-I Angle, ${ }^{\circ}$ & $\mathrm{I}-\mathrm{I}$ in $\mathrm{I}_{3}{ }^{-}, \AA$ \\
\hline $2 a$ & S2 .. I2: 3.707 & C1-S2 ... I2: 142.27 & S2 .. I2-I4: 110.54 & $2.917 ; 2.917$ \\
\hline $2 b$ & $\begin{array}{c}\mathrm{S} 2 \ldots \mathrm{I} 2: 3.775 \\
\mathrm{~S} 2 \mathrm{~b} \ldots \mathrm{I} 2: 3.778\end{array}$ & $\begin{array}{c}\text { C1-S2 . . I2: } 161.54 \\
\text { C10-S2b ... I2: } 153.69\end{array}$ & $\begin{array}{l}\text { S2 ... I2-I1: 110.53; } \\
\text { S2b ... I2-I1: } 32.93\end{array}$ & $\begin{array}{l}\mathrm{I}_{3}^{-}(1): 2.912 ; 2.912 \\
\mathrm{I}_{3}^{-}(2): 2.931 ; 2.931\end{array}$ \\
\hline 2c & 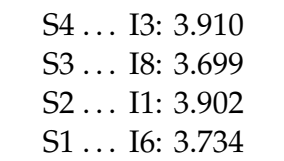 & $\begin{array}{l}\text { C9-S4 ... I3: } 165.72 \\
\text { C9-S3 ... I8: } 166.14 \\
\text { C1-S2 ... I1: } 172.07 \\
\text { C1-S1 ... I6: } 165.23\end{array}$ & $\begin{array}{l}\text { S4 ... I3-I2: } 96.39 \\
\text { S3 ... I8-I7: } 96.41 \\
\text { S2 ... I1-I2: } 77.78 \\
\text { S1 .. I I6-I7: } 96.74\end{array}$ & $\mathrm{I}_{3}^{-}(1): 2.904 ; 2.936$ \\
\hline
\end{tabular}

\subsection{Noncovalent Bonds Formed by Triiodide Anions: Electron Density Calculations}

In crystal $2 \mathrm{a}$, there is a typical halogen bond between the terminal iodine atom $\mathrm{I} 4$ of the triiodide anion and a covalently bound iodine atom I5 as part of the $\mathrm{CH}-\mathrm{I}$ fragment. Both the I4 and I2 atoms of the triiodide anion in crystal 2a form the chalcogen bonds with $\mathrm{S}$ atoms of the heterocyclic cation. In the triiodide anion of crystal $2 b$, both terminal atoms form two $S \ldots$ I interactions with almost identical distances, but they differ in their C-S . . I and S . . I-I angle values (Table 2); the central I1 and terminal I2 atoms are also involved in the I1 ... H9 and I2 .. H9 hydrogen bonds. Crystal structure $2 \mathrm{c}$ represents a case of a typical chalcogen bond where the C8 ... S2-I3 angle tends to $180^{\circ}$ and S2-I3-I1 is nearly a right angle, so that the mutual orientation of the electrophilic site of S2 and the nucleophilic region of I3 fits in the best way. Note that the terminal I atoms in the triiodide anions of $2 \mathrm{c}$ are involved in multiple noncovalent interactions, among which the most significant are chalcogen bonds S4 .. I3, S3 .. I8, S1 . I I6, S2 .. I1 and halogen bond I3 .. I5 with iodine atom I5 in the organic cation.

The representation of regions with a concentration and depletion of electron pairs in molecules and crystals can be done using the electron localization function (ELF) [7]. This function is dimensionless and is normalized from 0 to 1 , where the value 0.5 corresponds to the case of uniformly distributed one-electron gas. It is particularly interesting in the case of halogen atoms, as it is known that their electron concentration regions form the belt in the equatorial part of an atom [58]. ELF for I atoms in the triiodide anions (Figure 3) clearly reveals the regions of electron accumulation (shown in orange) and electrophilic sites-regions of electron depletion on the extension of the I-I bond. However, for the bound $S$ atom, the electrophilic site region is not always clearly seen in ELF, because it can be camouflaged by the electron concentration region that give a pronounced projection of high ELF values onto the considered plane of atomic interactions. This fact complicates the identification of the orientation of the bound S and I atoms. Accordingly, in such a case, we have applied the electronic criterion [48] that allows us to identify the atom (S or I) that has provided the electrophilic site and defined the name of interaction; in our case, it is either a halogen or chalcogen bond. The examples of the main considered S ... I interactions in the studied crystals are presented in Figures 3 and 4. 


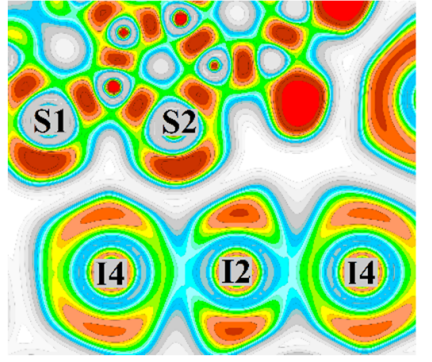

(a)

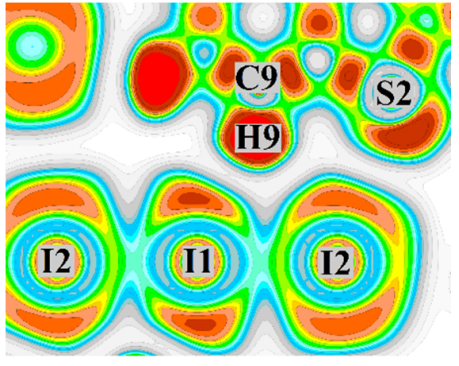

(b)

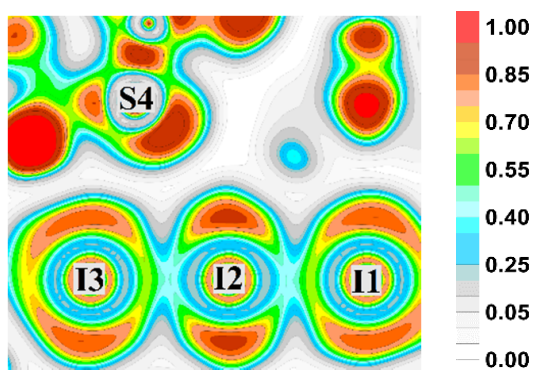

(c)

Figure 3. Electron localization function (ELF) distribution in S ... I motives in the structures (a) 2a (plane I4-I2 ... S2); (b) 2b (plane I1-I2 ... S2); and (c) 2c (plane I3-I2 ... S4).

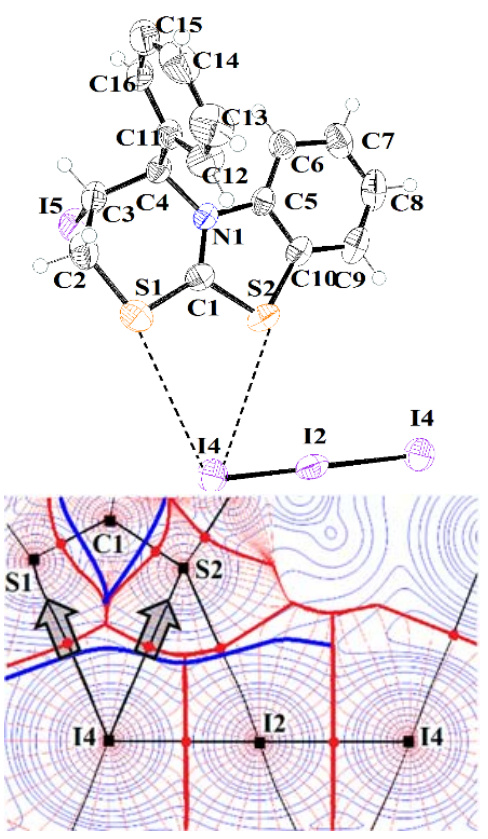

(a)

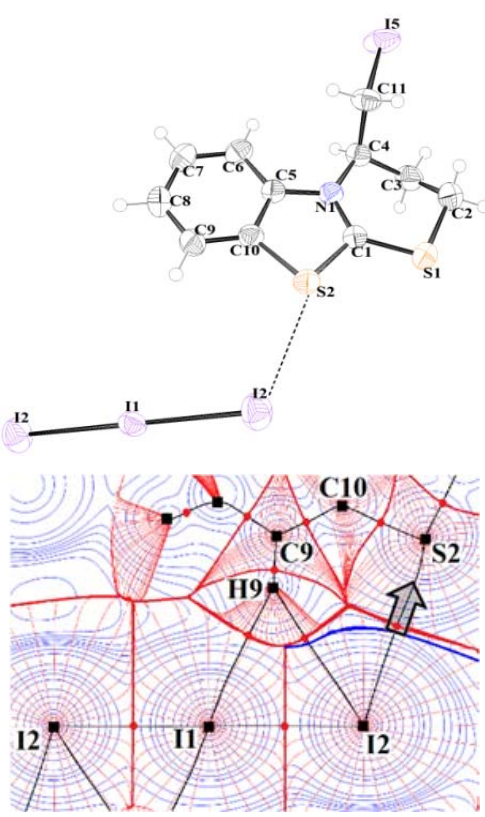

(b)

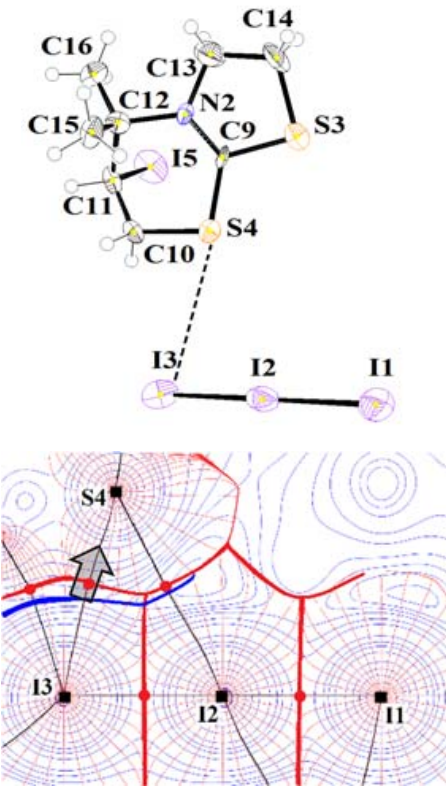

(c)

Figure 4. ORTEP diagrams of crystal structures illustrating the typical S ... I chalcogen bond (on top); on bottom: gradient fields, atomic basins and bond critical points of electron density (red lines and points), electrostatic potential distributions (blue lines) for typical chalcogen bonds (a) 2a (plane I4--I2 ... S2); (b) $2 b$ (plane I2-I1 ... S2); and (c) 2c (plane I3-I2 ... S4).

Let us consider the S ... I and other interactions in the studied crystals from the calculated electron density and electrostatic potential point of view as this approach has already been proven to be demonstrative $[59,60]$. Figure 4 illustrates the examples of S ... I chalcogen bonds in the considered crystals as well as the verification of non-covalent bonding type based on the electronic criteria. Within QTAIM [6], a zero-flux condition of the gradient vector field of electron density defines the boundaries of chemically bonded atoms, while basin boundaries in the electrostatic potential demarcate electrically neutral atomic fragments [61]. The map of the gradient field of electron density (Figure 4) allows us to recognize the boundaries of atomic basins. If this map is superimposed on the map of electrostatic potential distribution, it can be seen that the boundaries of electrically neutral atoms located using electrostatic potential do not coincide with the boundaries of atomic basins in electron density. This means that the fraction of electrons formally belonging to I atoms are attracted to $S$ nuclei along the highlighted directions. This is the general feature of chalcogen bonding. The images in Figure 4 are accompanied by the bond critical points (bcp) with values of electron density given in Table S3. 
As a simplification, the order of electron density and electrostatic potential minima along the $S$... I line can give a clue about the localization of the electrophilic site for typical and unobvious cases of halogen/chalcogen bonding. In this case, the formulation of previously suggested electronic criterion becomes more demonstrative. For the S1 ... I4 (2a), S2 .. I I (2b) and S4 ... I3 (2c) bonds in Figure 5, the minima of electrostatic potential (ESP) are located at the side of the I atoms donating electrons; the minima of electron density (ED) are placed closer to the $S$ atoms which deliver their electrophilic site for noncovalent bonding. The arrows in Figure 5 show the direction in which the electron density of the I atom is attracted to the electrophilic site of the $S$ atom. Thus, for all the cases of illustrated I ... $\mathrm{S}$ noncovalent bonds in $2 \mathrm{a}-2 \mathrm{c}$, we ascribe such interactions to a chalcogen bonding.

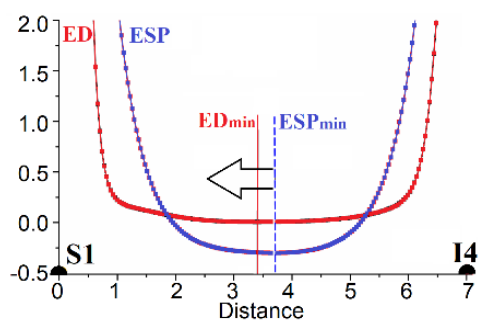

(a)

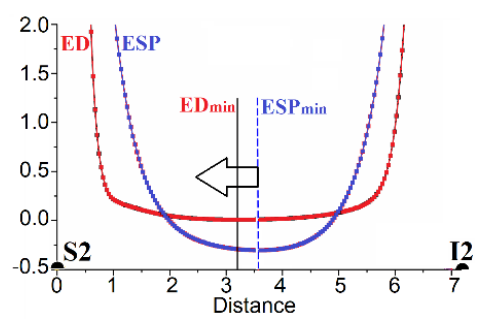

(b)

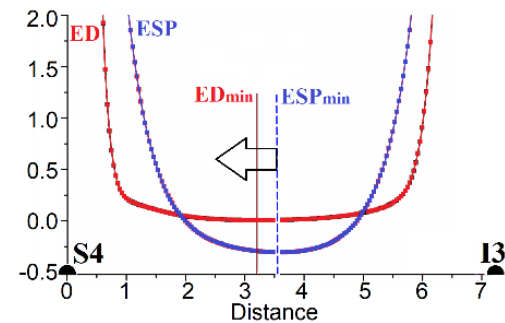

(c)

Figure 5. One-dimensional distributions of electron density (ED) and electrostatic potential (ESP) functions (a.u.) along the S ... I chalcogen bonds in $2 \mathrm{a}(\mathbf{a}), 2 \mathrm{~b}(\mathbf{b})$ and $2 \mathrm{c}(\mathbf{c})$ illustrating that the positions of electron density minimum $\left(\mathrm{ED}_{\mathrm{min}}\right)$ are closer to the $\mathrm{S}$ atoms; interatomic distances are in Bohr.

\subsection{Raman Spectroscopy Data}

Experimental Raman spectra of the studied crystals are presented in Figure 6. On the spectrum of crystal 2c, we clearly see two overlapping bands corresponding to the two symmetrically independent triiodide anions in the crystallographic cell. As both of them are symmetric, we see only the band of symmetric stretching vibration of the triiodide anion at $112.1 \mathrm{~cm}^{-1}$ and $113.7 \mathrm{~cm}^{-1}$ and do not see the band of antisymmetric vibration, usually observed in the range of $120-140 \mathrm{~cm}^{-1}$ [30].

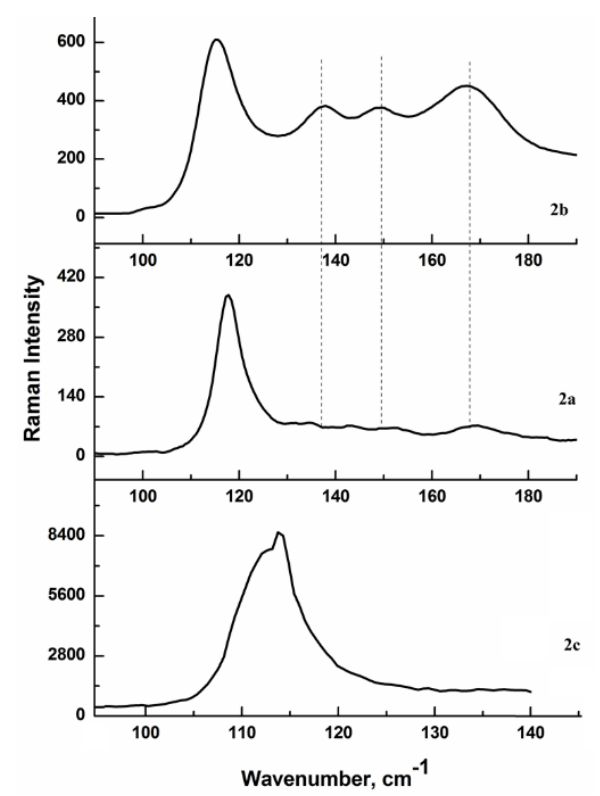

Figure 6. Experimental Raman spectra of crystals 2a-c in the low-frequency region.

The spectra of crystals $2 \mathrm{a}$ and $2 \mathrm{~b}$ are very similar and have weak bands at $138 \mathrm{~cm}^{-1}, 149 \mathrm{~cm}^{-1}$ and $168 \mathrm{~cm}^{-1}$, which are not attributed to the anionic vibrations and relate to libration and deformational 
vibrations of the tricyclic dihydrobenzothiazolo[2,3-b]thiazin-5-ium system. The intense triiodide vibration bands are located at $118 \mathrm{~cm}^{-1}(2 \mathrm{a})$ and $115 \mathrm{~cm}^{-1}(2 \mathrm{~b})$.

The correlation between the I-I bond lengths in the triiodide anion and the observed experimental wavenumbers of symmetric vibration is not so clear and evident as in case of iodine complexes $[62,63]$. For example, one of the triiodide anions in the crystal 2c has the same bond length as in 2a (2.9170 $\AA)$, but its wavenumber is much lower: $113 \mathrm{~cm}^{-1}(2 \mathrm{c})$ and $118 \mathrm{~cm}^{-1}(2 \mathrm{a})$, respectively. Such a spectral difference may reveal the effects that are beyond the geometric contribution on the level of bond length analysis and may be due to the effect of noncovalent interactions and crystal surrounding. Thus, as the isolated triiodide in $2 \mathrm{c}$ demonstrates a lower wavenumber, it has weaker I-I bonding within the triiodide anion in comparison to the anion in crystal 2a, demonstrating the band at $118 \mathrm{~cm}^{-1}$.

Such features of bonding strength in triiodide anions according to spectral data are also reflected in quantum-topological analysis of electron density. The electron density value at the bond critical point of the I-I bond in the triiodide anion is slightly higher in crystal $2 \mathrm{a}(0.0433 \mathrm{a}$.u.) than in crystal 2c (0.0419 a.u.), although the calculated equilibrium distances in these structures are identical (Table 2).

This fact is in agreement with the experimental spectral data and electron density values at the I-I bond critical point. Thus, the combination of experimental Raman characteristics together with calculated electron density descriptors can enrich the understanding of bond properties within the triiodide anion beyond the geometric approach based on bond length analysis.

\subsection{Thermal Analysis Data}

Thermoanalytical curves of TG-DSC analysis for crystals 2a-c are presented in Figure 7. The summary of the decomposition characteristics can be found in Table 3. All samples demonstrate multistep decomposition and rather high thermal stability for polyiodides; decomposition in all cases starts above $150{ }^{\circ} \mathrm{C}$.

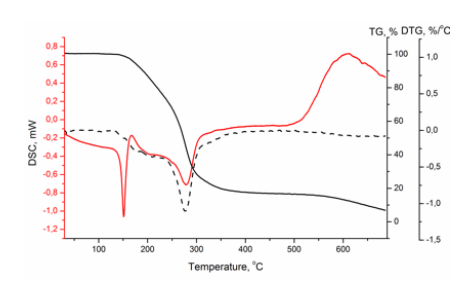

(a)

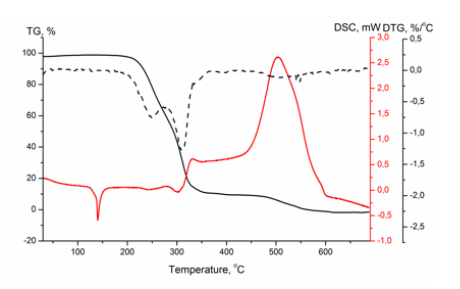

(b)

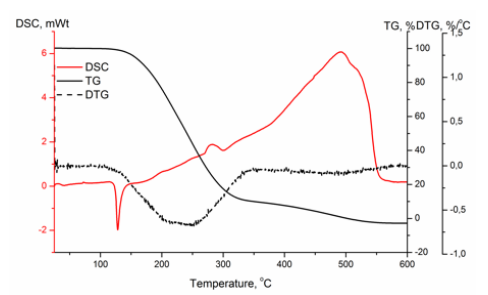

(c)

Figure 7. Thermogravimetric (TG), differential scanning calorimetry (DSC) and differential thermogravimetric (DTG) curves of crystals: $2 a(\mathbf{a}), 2 b(\mathbf{b})$ and $2 c(\mathbf{c})$.

Table 3. Thermal decomposition features of crystals 2a-c.

\begin{tabular}{cccc}
\hline & $\mathbf{2 a}$ & $\mathbf{2 b}$ & $\mathbf{2 c}$ \\
\hline Melting Point $\left({ }^{\circ} \mathrm{C}\right)$ & 141 & 127 & 122.5 \\
Decomposition start $\left({ }^{\circ} \mathrm{C}\right)$ & $162^{*}$ smooth & 222 & 160 \\
DTG peak $1\left({ }^{\circ} \mathrm{C}\right)$ & $180-210$ & 249 & 215 \\
DTG peak $2\left({ }^{\circ} \mathrm{C}\right)$ & 277 & 310 & 252 \\
Mass loss, peak 1 and $2(\%)$ & 83.4 & 89.9 & 90.3 \\
\hline
\end{tabular}

We can attempt to compare thermal decomposition and melting temperatures in the series of heterocyclic derivatives with the thiazolo-thiazinium fragment and with the same anion composition in order to try and find some trends due to differences in noncovalent interactions in the analyzed structures. A comparison of the data listed in Tables 2 and 3 shows that melting points decrease in the row $2 a>2 b>2 c$ (Table 1). The structural complexity of cations reduces in the order $2 a-2 b-2 c$ from the tricyclic system with the voluminous phenyl substituent (2a) to the same tricyclic system but with 
the small $-\mathrm{CH}_{2} \mathrm{I}$ substituent (2b) to the bicyclic thiazolo-thiazinium system (2c), leading to a lower melting point for structure 2c.

All studied triiodides tend to decompose only in the melt (no mass loss is observed before the melting point), although here the universal trend is not so evident: structure $2 \mathrm{~b}$ demonstrates remarkably high thermal stability $\left(222{ }^{\circ} \mathrm{C}\right.$, almost a $100{ }^{\circ} \mathrm{C}$ stability range of the melt), which is significantly higher than that for the other two structures. This fact may be due to the existence of four S ... I interactions involving both the terminal iodine atoms of triiodide anion in $2 b$, organized in such a way that the anion is trapped into the cage of four neighboring organic cations (Figure $3 b$ ). This fact can lead to a higher retention of iodine in the melt, as typically the first decomposition stage of polyiodides usually includes the loss of $\mathrm{I}_{2}$ from the triiodide anion $[64,65]$. Similar conclusions concerning melting and decomposition of crystals with $\mathrm{C}-\mathrm{Se} \ldots \mathrm{O} / \mathrm{N}$ chalcogen bonds were found in a recent study [66].

The crystal structures of compounds $2 \mathrm{a}$ and $2 \mathrm{c}$ are similar to the zigzag-like location of triiodide anions, while the crystal structure of $2 \mathrm{~b}$ demonstrates layered packing of organic cations, as the benzothiazolo-thiazinuim cycle is flatter than the corresponding thiazolo-thiazinium and especially than phenyl-substituted $2 a$. Such layered organization in crystal $2 b$ can lead to more effective capsulation of triiodide anions in the cage of the cations, which can be one of possible reasons for comparatively higher retention of iodine in the melt in the row of triiodides $2 a-2 b-2 c$. Based on quantum-topological analysis of the electron density properties (Tables S3 and S4) and thermal analysis data, we can make some inferences. Firstly, both triiodides in structure $2 \mathrm{~b}$ are relatively weakly bound with crystalline surrounding; the only rather strong chalcogen bond S ... I ( $3.7208 \AA$, the value of electron density at the bond critical point $\left(\mathrm{r}_{\mathrm{bcp}}\right)=0.008$ a.u.) dominates. Secondly, in structure $2 \mathrm{a}$, we observe a moderate number of bond critical points but only for one symmetrically independent triiodide anion. The other is weakly bound to the crystal surrounding. Thirdly, in structure $2 c$, the numerous weak I ... H interactions are formed with each of the triiodide anions; one relatively short and strong I ... H hydrogen bond ( $2.8940 \AA,\left(\mathrm{r}_{\mathrm{bcp}}\right)=0.0114$ a.u.) stands out from all others. Chalcogen S ... I and halogen I ... I bonds between the cation and anion are also observed. In general, the $2 \mathrm{a}>$ $2 b>2 c$ melting point order is reversed for the overall density in the bond critical points of cation ... cation $(\mathrm{H} \ldots \mathrm{H}, \mathrm{C} \ldots \mathrm{I}, \mathrm{S} \ldots \mathrm{H}, \mathrm{C} \ldots \mathrm{C})$ interactions.

\section{Conclusions}

The synthesized crystal structures of $2 H$-benzo[4,5]thiazolo[2,3-b][1,3]thiazin-5-ium and 3,5,6,7-tetrahydro-2H-thiazolo[2,3-b][1,3]thiazin-4-ium triiodides were characterized using single crystal X-ray diffraction, Raman spectroscopy, and thermal analysis. The type of noncovalent bonds were described on the basis of periodic quantum-chemical calculations revealing cation .... anion chalcogen S ... I bonds and halogen I ... I bonds. In the cases of ambiguous mutual orientation of noncovalently bound atoms, the electronic criterion of the disposition of electron density and electrostatic potential minima was used; all considered S ... I interactions were categorized as chalcogen bonds. Raman spectra and local properties of electron density allowed us to reveal the influence of noncovalent bonds on the properties of triiodide anions with equal bond length: the more bound iodine atoms was the reason for a stronger I-I bond within the triiodide anion. The thermal analysis data showed that the layered packing of benzothiazolo-thiazinium triiodide promoted effective capsulation of triiodide anions due to hydrogen and chalcogen bonding and might act as a stabilizing factor, providing comparatively higher thermal stability and iodine retention in the melt.

Supplementary Materials: The following are available online at http://www.mdpi.com/2073-4352/9/10/506/s1, Table S1: Bond lengths for triiodides 2a, 2b and 2c, Table S2: Bond angles for triiodides 2a, 2b and 2c, Figure S1: Crystal habit of triiodide 2c (ruby red) and corresponding monoiodide (light yellow) under $4 \times$ microscope magnification, Table S3: Local properties at bond critical points (bcp) of noncovalent interactions formed by triiodide anions in $2 \mathrm{a}, 2 \mathrm{~b}$ and $2 \mathrm{c}$ crystals, Table S4: Local properties at bond critical points of noncovalent interactions formed by organic cations in $2 \mathrm{a}, 2 \mathrm{~b}$ and $2 \mathrm{c}$. 
Author Contributions: Conceptualization, E.B.; Funding acquisition, D.K., V.S. and E.B.; Investigation, I.Y., N.T. and V.S.; Methodology, E.B.; Project administration, D.K. and E.B.; Resources, N.T.; Supervision, D.K. and E.B.; Validation, I.Y. and E.B.; Visualization, I.Y. and E.B.; Writing-original draft, I.Y., N.T.; Writing-review and editing, E.B.

Funding: The work was supported by The Government of Russian Federation decree №211, agreement № 02.A03.21.0011 and by the Ministry of Education and Science of the Russian Federation: grant 4.9665.2017/8.9 (N.T. and D.K.), grant 4.6151.2017/8.9 (V.S.) and 4.1157.2017/4.6 (I.Y. and E.B.).

Conflicts of Interest: The authors declare no conflict of interest.

\section{References}

1. Vogel, L.; Wonner, P.; Huber, S.M. Chalcogen Bonding: An Overview. Angew. Chem. 2019, 58, $1880-1891$. [CrossRef] [PubMed]

2. Politzer, P.; Murray, J.S.; Clark, T. Halogen Bonding: An Electrostatically-Driven Highly Directional Noncovalent Interaction. Phys. Chem. Chem. Phys. 2010, 12, 7748-7757. [CrossRef] [PubMed]

3. Desiraju, G.R.; Ho, P.S.; Kloo, L.; Legon, A.C.; Marquardt, R.; Metrangolo, P.; Politzer, P.; Resnati, G.; Rissanen, K. Definition of the Halogen Bond (IUPAC Recommendations 2013). Pure Appl. Chem. 2013, 85, 1711-1713. [CrossRef]

4. Aakeroy, C.B.; Bryce, D.L.; Desiraju, G.R.; Frontera, A.; Legon, A.C.; Nicotra, F.; Rissanen, K.; Scheiner, S.; Terraneo, G.; Metrangolo, P.; et al. Definition of the chalcogen bond. Iupac Recomm. 2019. [CrossRef]

5. Politzer, P.; Murray, J.S. An Overview of Strengths and Directionalities of Noncovalent Interactions: $\sigma$-Holes and $\rho$-Holes. Crystals 2019, 9, 165. [CrossRef]

6. Bader, R.F.W. Atoms in Molecules: A Quantum Theory; Clarendon Press: Oxford, UK, 1990; pp. 1-438.

7. Becke, A.D.; Edgecombe, K.E. A simple measure of electron localization in atomic and molecular systems. J. Chem. Phys. 1990, 92, 5397-5403. [CrossRef]

8. Tsirelson, V.G.; Zhou, P.F.; Tang, T.-H.; Bader, R.F.W. Topological definition of crystal structure: Determination of the bonded interactions in solid molecular chlorine. Acta Crystallogr. Sect. A 1995, A51, 143-153. [CrossRef]

9. Johnson, E.R.; Keinan, S.; Mori-Sánchez, P.; Contreras-García, J.; Cohen, A.J.; Yang, W. Revealing Non-Covalent Interaction. J. Am. Chem. Soc. 2010, 132, 6498-6506. [CrossRef]

10. Adonin, S.A.; Bondarenko, M.A.; Novikov, A.S.; Abramov, P.A.; Plyusnin, P.E.; Sokolov, M.N.; Fedin, V.P. Halogen Bonding-assisted Assembly of Bromoantimonate (V) and Polybromide-bromoantimonate-based Frameworks. CrystEngComm 2019, 2, 850-856. [CrossRef]

11. Adonin, S.A.; Gorokh, I.D.; Abramov, P.A.; Novikov, A.S.; Korolkov, I.V.; Sokolov, M.N.; Fedin, V.P. Chlorobismuthates Trapping Dibromine: Formation of Two-Dimensional Supramolecular Polyhalide Networks with Br2 Linkers. Eur. J. Inorg. Chem. 2017, 4925-4929. [CrossRef]

12. Adonin, S.A.; Bondarenko, M.A.; Abramov, P.A.; Novikov, A.S.; Plyusnin, P.E.; Sokolov, M.N.; Fedin, V.P. A Bromo- and polybromoantimonates (V): Structural and theoretical studies of hybrid halogen-rich halometalate frameworks. Chem. Eur. J. 2018, 24, 10165-10170. [CrossRef] [PubMed]

13. Kukkonen, E.; Malinen, H.; Haukka, M.; Konu, J. Reactivity of 4-Aminopyridine with Halogens and Interhalogens: Weak Interactions Supported Networks of 4-Aminopyridine and 4-Aminopyridinium. Cryst. Growth Des. 2019, 19, 2434-2445. [CrossRef]

14. Gross, M.M.; Manthiram, A. Long-Life Polysulfide-Polyhalide Batteries with a Mediator-Ion Solid Electrolyte. ACS Appl. Energy Mater. 2019, 2, 3445-3451. [CrossRef]

15. Sonnenberg, K.; Pröhm, P.; Schwarze, N.; Müller, C.; Beckers, H.; Riedel, S. Investigation of Large Polychloride Anions: [Cl11]-, [Cl12]2-, and [Cl13]-. Angew. Chem. Int. Ed. 2018, 57, 9136-9140. [CrossRef] [PubMed]

16. Savastano, M.; Martínez-Camarena, Á.; Bazzicalupi, C.; Delgado-Pinar, E.; Llinares, J.M.; Mariani, P.; Verdejo, B.; García-España, E.; Bianchi, A. Stabilization of Supramolecular Networks of Polyiodides with Protonated Small Tetra-azacyclophanes. Inorganics 2019, 7, 48. [CrossRef]

17. Yu, H.-L.; He, Y.-C.; Zhao, F.-H.; Wang, Y.; Wang, A.-N.; Hao, M.-G.; Si, Z.-S.; You, J. Synthesis, Structure and Properties of a New Polyiodide Compound with the 1D $\rightarrow$ 3D Interdigitated Architecture. Polyhedron 2019, 169, 183-186. [CrossRef]

18. McDaniel, J.G.; Yethiraj, A. Grotthuss Transport of Iodide in EMIM/I3 Ionic Crystal. J. Phys. Chem. B 2018, 122, 250-257. [CrossRef] [PubMed] 
19. Shestimerova, T.A.; Bykov, M.A.; Wei, Z.; Dikarev, E.V.; Shevelkov, A.V. Crystal Structure and Two-level Supramolecular Organization of Glycinium Triiodide. Russ. Chem. Bull. 2019, 68, 1520-1524. [CrossRef]

20. Shestimerova, T.A.; Golubev, N.A.; Yelavik, N.A.; Bykov, M.A.; Grigorieva, A.V.; Wei, Z.; Dikarev, E.V.; Shevelkov, A.V. Role of I2 Molecules and Weak Interactions in Supramolecular Assembling of Pseudo-Three-Dimensional Hybrid Bismuth Polyiodides: Synthesis, Structure, and Optical Properties of Phenylenediammonium Polyiodobismuthate(III). Cryst. Growth Des. 2018, 18, 2572-2578. [CrossRef]

21. Savinkina, E.V.; Golubev, D.V.; Grigoriev, M.S. Synthesis, Characterization, and Crystal Structures of Iodides and Polyiodides of Scandium Complexes with Urea and Acetamide. J. Coord. Chem. 2019, 72, 347-357. [CrossRef]

22. Ma, L.; Peng, H.; Lu, X.; Liu, L.; Shao, X. Building up 1-D, 2-D, and 3-D Polyiodide Frameworks by Finely Tuning the Size of Aryls on Ar-S-TTF in the Charge-Transfer (CT) Complexes of Ar-S-TTFs and Iodine. Chin. J. Chem. 2018, 36, 845-850. [CrossRef]

23. Blake, A.J.; Li, W.-S.; Lippolis, V.; Schröder, M.; Devillanova, F.A.; Gould, R.O.; Parsons, S.; Radek, C. Template self-assembly of polyiodide networks. Chem. Soc. Rev. 1998, 27, 195-206. [CrossRef]

24. Rybkovskiy, D.V.; Impellizzeri, A.; Obraztsova, E.D.; Ewels, C.P. Polyiodide Structures in Thin Single-walled Carbon Nanotubes: A large-scale Density-functional Study. Carbon 2019, 142, 123-130. [CrossRef]

25. Li,H.-H.; Chen, Z.-R.; Cheng, L.-C.; Liu, J.-B.; Chen, X.-B.; Li, J.-Q. A New Hybrid Optical Semiconductor Based on Polymeric Iodoplumbate Co-Templated by Both Organic Cation and Polyiodide Anion. Cryst. Growth Des. 2008, 8, 4355-4358. [CrossRef]

26. Wlaźlak, E.; Kalinowska-Tłuścik, E.J.; Nitek, W.; Klejna, S.; Mech, K.; Macyk, W.; Szaciłowski, K. Triiodide Organic Salts: Photoelectrochemistry at the Border between Insulators and Semiconductors. Chemelectrochem 2018, 5, 3486-3497. [CrossRef]

27. Poręba, T.; Ernst, M.; Zimmer, D.; Macchi, P.; Casati, N. Pressure-Induced Polymerization and Electrical Conductivity of a Polyiodide. Angew. Chem. Int. Ed. 2019, 58, 6625-6629. [CrossRef]

28. Starkholm, A.; Kloo, L.; Svensson, P.H. Polyiodide hybrid perovskites: A strategy to convert intrinsic 2D systems into 3D photovoltaic materials. ACS Appl. Energy Mater. 2019, 2, 477-485. [CrossRef]

29. Yin, Z.; Wang, Q.-X.; Zeng, M.-H. Iodine Release and Recovery, Influence of Polyiodide Anions on Electrical Conductivity and Nonlinear Optical Activity in an Interdigitated and Interpenetrated Bipillared-Bilayer Metal-Organic Framework. J. Am. Chem. Soc. 2012, 134, 4857-4863. [CrossRef]

30. Svensson, P.H.; Kloo, L. Synthesis, Structure, and Bonding in Polyiodide and Metal Iodide-Iodine Systems. Chem. Rev. 2003, 103, 1649-1684.

31. Corban, G.J.; Hadjikakou, S.K.; Hadjiliadis, N.; Kubicki, M.; Tiekink, E.R.T.; Butler, I.S.; Drougas, E.; Kosmas, A.M. Synthesis, Structural Characterization, and Computational Studies of Novel Diiodine Adducts with the Heterocyclic Thioamides N-Methylbenzothiazole-2-thione and Benzimidazole-2-thione: Implications with the Mechanism of Action of Antithyroid Drugs. Inorg. Chem. 2005, 44, 8617-8627. [CrossRef]

32. Roy, G.; Nethaji, M.; Mugesh, G. Interaction of anti-thyroid drugs with iodine: The isolation of two unusual ionic compounds derived from Se-methimazole. Org. Biomol. Chem. 2006, 4, 2883-2887. [CrossRef] [PubMed]

33. Arca, M.; Aragoni, M.C.; Devillanova, F.A.; Garau, A.; Isaia, F.; Lippolis, V.; Mancini, A.; Verani, G. Structure-Activity Relationships of Synthetic Coumarins as HIV-1 Inhibitors. Bioinorg. Chem. Appl. 2006, 2006, 1-9. [CrossRef] [PubMed]

34. Rabie, U.M.; Abou-El-Wafa, M.H.; Nassar, H. In vitro simulation of the chemical scenario of the action of an anti-thyroid drug: Charge transfer interaction of thiazolidine-2-thione with iodine. Spectrochim. Acta A Mol. Biomol. Spectrosc. 2011, 78, 512-517. [CrossRef] [PubMed]

35. Refat, M.S.; El-Hawary, W.F.; Moussa, M.A. IR, 1H NMR, mass, XRD and TGA/DTA investigations on the ciprofloxacin/iodine charge-transfer complex. Spectrochim. Acta A Mol. Biomol. Spectrosc. 2011, 78, 1356-1363. [CrossRef] [PubMed]

36. El-Sheshtawy, H.S.; Salman, H.M.A.; El-Kemary, M. Halogen vs hydrogen bonding in thiazoline-2-thione stabilization with $\sigma$ - and $\pi$-electron acceptors adducts: Theoretical and experimental study. Spectrochim. Acta Part A Mol. Biomol. Spectrosc. 2015, 137, 442-449. [CrossRef] [PubMed]

37. Punyani, S.; Narayana, P.; Singh, H.; Vasudevan, P. Iodine based water disinfection: A review. J. Sci. Ind. Res. (India) 2006, 65, 116-120. 
38. Kulkarni, P.V.; Arora, V.; Rooney, A.S.; White, C.; Bennett, M.; Antich, P.P.; Bonte, F.J. Radiolabeled probes for imaging Alzheimer's plaques. Nucl. Instrum. Methods Phys. Res. B 2005, B241, 676-680. [CrossRef]

39. Duan, Y.; Tang, Q.; Chen, Y.; Zhao, Z.; Lv, Y.; Hou, M.; Yang, P.; He, B.; Yu, L. Solid-state dye-sensitized solar cells from poly(ethylene oxide)/polyaniline electrolytes with catalytic and hole-transporting characteristics. J. Mater. Chem. A 2015, 3, 5368-5374. [CrossRef]

40. Matsumoto, S.; Sumida, R.; Tan, S.E.; Akazome, M. Synthesis of Iodinated Thiazolo[2,3-a]isoquinolinium salts and their Crystal Structures with/without Halogen Bond. Heterocycles 2018, 97, 755-775. [CrossRef]

41. Kuznetsova, E.A.; Zhuravlev, S.V.; Stepanova, T.N. Synthesis and Properties of Derivatives of 2-Mercaptobenzothiazole. VIII. (Perhydro-1,3-thiazino)[2,3-b]benzothiazolines. Chem. Heterocycl. Comp. 1969, 5, 467-469. [CrossRef]

42. Gregory, J.; Wei, P.H.L. Thiazolo[2,3-b]benzo(and azobenzo)-thiazole Derivatives, Process for their Preparation and Pharmaceutical Compositions Containing Them. EP Patent 0021773, 1 January 1981.

43. Beard, C.C. 5(6)-Benzene Ring Substituted Benzimidazole-2-carbamate Derivatives Having Anti-protozoal Activity. U.S. Patent 4031228, 22 June 1977.

44. Clark, A.D.; Sykes, P. Thiazolinium salts and their reactions with nucleophiles. J. Chem. Soc. 1971, $103-110$. [CrossRef]

45. Deplano, P.; Devillanova, F.; Francesco, A.; Ferraro, J.R.; Mercuri, M.L.; Lippolis, V.; Trogu, E.F. FT-Raman Study on Charge-Transfer Polyiodide Complexes and Comparison with Resonance Raman Results. Appl. Spectrosc. 1994, 48, 1236-1241. [CrossRef]

46. Bartashevich, E.V.; Yushina, I.D.; Stash, A.I.; Tsirelson, V.G. Halogen Bonding and Other Iodine Interactions in Crystals of Dihydrothiazolo(oxazino)quinolinium Oligoiodides from the Electron-Density Viewpoint. Cryst. Growth Des. 2014, 14, 5674-5684. [CrossRef]

47. Yu, H.; Yan, L.; He, Y.; Meng, H.; Huang, W. An Unusual Photoconductive Property of Polyiodide and Enhancement by Catenating with 3-Thiophenemethylamine Salt. Chem. Commun. 2017, 53, 432-435. [CrossRef] [PubMed]

48. Bartashevich, E.V.; Mukhitdinova, S.E.; Yushina, I.D.; Tsirelson, V.G. Electronic criterion for categorizing the chalcogen and halogen bonds: Sulfur-iodine interactions in crystals. Acta Crystallogr. Sect. B 2019, B75, 117-126. [CrossRef]

49. Tarasova, N.M.; Kim, D.G. Synthesis and Halocyclization of Allyl Derivatives of 4,5-Dihydro-1,3-thiazol2-thione. Bull. South Ural State Univ. Sect. Chem. 2015, 7, 4-10.

50. Bruker. SMART and SAINT-Plus, Versions 5.0; Data Collection and Processing Software for the SMART System; Bruker AXS Inc.: Madison, WI, USA, 1998.

51. Bruker. SHELXTL/PC, Versions 5.10; An Integrated System for Solving, Refining and Displaying Crystal Structures from Diffraction Data; Bruker AXS Inc.: Madison, WI, USA, 1998.

52. Dolomanov, O.V.; Bourhis, L.J.; Gildea, R.J.; Howard, J.A.K.; Puschmann, H. OLEX2: A Complete Structure Solution, Refinement and Analysis Program. J. Appl. Cryst. 2009, 42, 339-341. [CrossRef]

53. Yushina, I.D.; Kolesov, B.A.; Bartashevich, E.V. Raman Spectroscopy Study of New Thia- and Oxazinoquinolinium Triodides. New J. Chem. 2015, 39, 6163-6170. [CrossRef]

54. Dovesi, R.; Erba, A.; Orlando, R.; Zicovich-Wilson, C.M.; Civalleri, B.; Maschio, L.; Rerat, M.; Casassa, S.; Baima, J.; Salustro, S.; et al. Quantum-mechanical condensed matter simulations with CRYSTAL. Wires Comput. Mol. Sci. 2018, 8, e1360. [CrossRef]

55. Iodine Basis Set. Available online: http://www.tcm.phy.cam.ac.uk/ \{\}mdt26/basis_sets/I_basis.txt (accessed on 27 September 2019).

56. Gatti, C.; Saunders, V.R.; Roetti, C. Crystal field effects on the topological properties of the electron density in molecular crystals: The case of urea. J. Chem. Phys. 1994, 101, 10686-10696. [CrossRef]

57. Gatti, C.; Casassa, S. TOPOND14 User's Manual; CNR-ISTM of Milano: Milano, Italy, 2013.

58. Clark, T. o-Holes. Wires Comput. Mol. Sci. 2013, 3, 13-20. [CrossRef]

59. Bartashevich, E.V.; Yushina, I.D.; Kropotina, K.K.; Muhitdinova, S.E.; Tsirelson, V.G. Testing the Tools for Revealing and Characterizing the Iodine-Iodine Halogen Bond in Crystals. Acta Crystallogr. Sect. B 2017, B73, 217-226. [CrossRef] [PubMed]

60. Bol'shakov, O.I.; Yushina, I.D.; Bartashevich, E.V.; Nelyubina, Y.V.; Aysin, R.R.; Rakitin, O.A. Asymmetric triiodide-diiodine interactions in the crystal of (Z)-4-chloro-5-((2-((4-chloro-5H-1,2,3-dithiazol-5-ylidene) amino)phenyl)amino)-1,2,3-dithiazol-1-ium oligoiodide. Struct. Chem. 2017, 28, 1927-1934. [CrossRef] 
61. Tsirelson, V.G.; Avilov, A.S.; Lepeshov, G.G.; Kulygin, A.K.; Stahn, J.; Pietsch, U.; Spence, J.C.H. Quantitative Analysis of the Electrostatic Potential in Rock-Salt Crystals Using Accurate Electron Diffraction Data. J. Phys. Chem. B 2001, 105, 5068-5074. [CrossRef]

62. Bartashevich, E.V.; Grigoreva, E.A.; Yushina, I.D.; Bulatova, L.M.; Tsirelson, V.G. Modern level for properties prediction of iodine-containing organic compounds: The halogen bonds formed by iodine. Russ. Chem. Bull. 2017, 66, 1345-1356. [CrossRef]

63. Arca, M.; Aragoni, M.C.; Devillanova, F.A.; Garau, A.; Isaia, F.; Lippolis, V.; Mancini, A.; Verani, G. Reactions between chalcogen donors and dihalogens/interalogens: Typology of products and their characterization by FT-Raman spectroscopy. Bioinorg. Chem. Appl. 2006, 2006, 58937. [CrossRef] [PubMed]

64. Yushina, I.D.; Rudakov, B.V.; Krivtsov, I.V.; Bartashevich, E.V. Thermal decomposition of tetraalkylammonium iodides. J. Anal. Calorim. 2014, 118, 425-429. [CrossRef]

65. Yushina, I.D.; Pikhulya, D.G.; Bartashevich, E.V. The features of iodine loss at high temperatures. The case study of crystalline thiazoloquinolinium polyiodides. J. Therm. Anal. Calorim. 2019. [CrossRef]

66. Wang, H.; Liu, J.; Wang, W. Intermolecular and very strong intramolecular $\mathrm{C}-\mathrm{SeO} / \mathrm{N}$ chalcogen bonds in nitrophenyl selenocyanate crystals. Phys. Chem. Chem. Phys. 2018, 20, 5227-5234. [CrossRef]

(C) 2019 by the authors. Licensee MDPI, Basel, Switzerland. This article is an open access article distributed under the terms and conditions of the Creative Commons Attribution (CC BY) license (http://creativecommons.org/licenses/by/4.0/). 